\title{
Gene expression analysis reveals novel altered genes in nasal polyps
}

\author{
ERICA BABETO $^{1}$, MARÍLIA DE FREITAS CALMON ${ }^{1}$, PAOLA JOCELAN SCARIN PROVAZZI ${ }^{1}$, \\ JUCIMARA COLOMBO ${ }^{1}$, JOSÉ ANTÔNIO CORDEIRO ${ }^{2}$, JANE LOPES BONILHA ${ }^{3}$, \\ ATÍLIO MAXIMINO FERNANDES ${ }^{3,4}$ and PAULA RAHAL ${ }^{1}$
}

${ }^{1}$ Laboratory of Genomics Studies, São Paulo State University - UNESP; Departments of ${ }^{2}$ Epidemiology and Collective Health, ${ }^{3}$ Pathology, and ${ }^{4}$ Otorhinolaryngology and Head and Neck Surgery, College of Medicine, São José do Rio Preto

School of Medicine - FAMERP, São José do Rio Preto, SP, Brazil

Received November 12, 2009; Accepted March 4, 2010

\section{DOI: $10.3892 / \mathrm{mmr} 00000285$}

\begin{abstract}
Nasal polyposis (NP) is a chronic inflammatory disease of the nasal mucosa characterized by the infiltration of inflammatory cells, mainly eosinophils. Although nasal polyposis occurs in $4 \%$ of the population, its physiopathology remains unclear. The aim of this study was to identify and characterize differentially expressed genes that can be used in the prognosis, treatment and elucidation of this physiopathology. To identify novel genes differentially expressed in $\mathrm{NP}$, we applied real-time quantitative PCR to $11 \mathrm{NP}$ samples and to a pool of total RNA from a subset of 13 normal nasal mucosa samples from human autopsies. For selecting genes, the methylated $\mathrm{CpG}$ island amplification technique was used. Five differentially methylated clones (ATP2A1, NOVAl, $P L C D 3, S O L H$ and $T G F \beta I$ ) were identified. However, these genes presented methylated $\mathrm{CpG}$ islands between exons, i.e., not in the promoter regions of the genes. Thus, as shown by real-time PCR, the ATP2A1, SOLH, PLDC 3 and TGF $I$ genes were overexpressed in NP. The genes identified in this study are probably involved in some stage of the process of formation and development of nasal polyposis, as they were highly expressed in the nasal polyp samples.
\end{abstract}

\section{Introduction}

Nasal polyposis (NP) is a chronic proliferative inflammatory disease of the mucous membranes that affects the nasal and nasal sinus mucosa. NP is characterized by benign polypoid

Correspondence to: Dr Paula Rahal, Department of Biology, Instituto de Biociências, Letras e Ciências Exatas - IBILCE/UNESP, Cristóvão Colombo 2265, 15054-000 São José do Rio Preto, SP, Brazil

E-mail: rahalp@yahoo.com.br

Key words: ATP2A1, gene expression, nasal polyps, NOVA1, methylated $\mathrm{CpG}$ island amplification, $P L C D 3$, real-time PCR, $S O L H$, TGF $\beta I$ degeneration (1) with two or more symptoms, one of which is either nasal blockage/obstruction/congestion or nasal discharge (2). It is usually bilateral, and the peak of its incidence lies in the fourth decade of life, affecting $1-4 \%$ of the general population, with a 2.2:1 male/female ratio.

The origin of nasal polyps remains unclear, and an allergic origin is controversial. The pathogenesis of nasal polyps is probably multifactorial (2). This clinical condition can be associated with systemic diseases of the respiratory tract such as asthma, rhinitis, aspirin-intolerance, cystic fibrosis or primary cilia dyskinesia, or with more localized diseases such as chronic sinusitis with a dental or fungal focus of infection/ inflammation (3).

The condition is characterized by the presence of edematous fluid with sparse fibrous cells, proliferation and metaplasia of the respiratory epithelial layer, thickening of the basement membrane and local fibrosis (4). Apart from epithelial differentiation and overgrowth, a major feature of polyposis is the marked presence of inflammatory cells, particularly eosinophils and mast cells, which contribute to the formation, growth and maintenance of NP, acting on the epithelium and stroma of the polyps, promoting collagen synthesis and perpetuating the inflammatory process (5).

The treatment of NP and prevention against recurrence after surgery is based on the administration of corticosteroids, but such medical treatment is often ineffective (6). The mechanism of action of corticosteroids may involve a multifactorial effect on various aspects of the inflammatory reaction (7).

Given the fact that the physiopathology of nasal polyposis is unknown, that its treatment is sometimes ineffective, and that research on NP markers is scarce (the most cited being on inflammatory mediators), it is evident that novel molecular markers are required for a better understanding of the physiopathology and treatment of NP.

In this study, we sought to identify gene expression in nasal polyps using real-time PCR. For the selection of the genes to be examined, the methylated $\mathrm{CpG}$ island amplification (MCA) technique, which is useful for both methylation analysis and the cloning of differentially methylated genes, was used. Changes in methylation patterns serve as important 
biomarkers in the physiopathology of several diseases, mainly tumors (8).

Thus, the aim of this study was to identify and to characterize differentially expressed genes in nasal polyps that may be involved in the aetiology and development of the disease generating knowledge for the prognosis, treatment and understanding of its pathophysiology.

\section{Materials and methods}

Patients and samples. This study was approved by the Research Ethics Committees of the Federal University of São Paulo School of Medicine (UNIFESP-EPM) and of the São José do Rio Preto School of Medicine (FAMERP). Written informed consent was obtained from all participants prior to sample collection.

Nasal polyposis patients were selected at the Department of Otolaryngology/Head and Neck Surgery of the São José do Rio Preto School of Medicine (FAMERP). Eleven patients, 8 male and 3 female, aged 35-72 years (mean age 53.9 years) were selected for the study. Patients had inflammatory NP requiring surgical intervention, evaluated according to medical history, clinical examination and biopsy. The medical history of the patients revealed that $8(72.7 \%)$ had symptoms of atopy, $1(9 \%)$ had asthma, and $9(36.4 \%)$ had nasal cytology compatible with allergic rhinitis (determined by a positive skin prick test). NP diagnoses were based on medical history and clinical examinations, including nasal endoscopic examination. The epidemiological data of the patients with nasal polyposis are presented in Table I. None of the patients had any disease requiring continuous medication.

As a control, 13 normal nasal mucosa samples from human autopsies were collected via biopsy, performed on the mucosa from the nasal middle meatus of the cadavers. The control group included 6 males and 8 females aged $45-86$ years (mean age of 56.7 years) with no history of sinonasal disease (causes of death were either car accident or myocardial infraction), nor any disease requiring continuous medication. Rhinoscopy was performed to confirm the absence of nasosinusal polyps. To ensure the histological quality of the autopsies, the samples were harvested within the first $8 \mathrm{~h}$ of death.

RNA extraction and RT-PCR. Nasal polyp and nasal mucosa specimens were pulverized under liquid nitrogen using a mortar and pestle, and total RNA was extracted with TRIzol Reagent (Life Technologies). To evaluate the quality of the RNA, the absorbency of each sample was determined by spectrophotometry at $260 / 280 \mathrm{~nm}$, and $\sim 1 \mu \mathrm{g}$ was loaded onto $1 \%$ agarose gel and resolved by electrophoresis. The gel was stained with ethidium bromide, and the $18 \mathrm{~S}$ and $28 \mathrm{~S}$ bands were visualized using ultraviolet (UV) light.

Approximately $5 \mu \mathrm{g}$ of total RNA from each sample was used to synthesize cDNA using a High-Capacity cDNA Archive kit (Applied Biosystems) according to the manufacturer's instructions. The quality of the cDNA was evaluated by PCR of the housekeeping gene $\beta$-actin. The primer sets were 5' to 3' GGCATCGTGATGGACTCCG and GCTGGAAGGTGGACAGCG. The PCR products were analyzed by electrophoresis on $1 \%$ agarose gel and stained with ethidium bromide.
Table I. Clinical data of the patients with nasosinusal polyposis.

\begin{tabular}{lccccc}
\hline Patients & Gender & Age & Asthma & Atopy & Nasal cytology \\
\hline 1 & M & 70 & - & - & - \\
2 & M & 79 & - & + & - \\
3 & F & 49 & - & + & + \\
4 & M & 53 & - & - & - \\
5 & F & 56 & - & - & - \\
6 & F & 61 & - & - & - \\
7 & M & 69 & - & - & - \\
8 & M & 40 & - & + & + \\
9 & M & 39 & + & + & + \\
10 & M & 54 & - & + & + \\
11 & M & 65 & - & - & - \\
\hline
\end{tabular}

DNA extraction. Nasal polyp and nasal mucosa specimens were collected and stored at $-20^{\circ} \mathrm{C}$ until DNA extraction. DNA was isolated using TRIzol Reagent (Life Technologies).

Methylated $C p G$ island amplification (MCA). MCA was performed as described previously (8). NP DNA (5 $\mu \mathrm{g})$ was digested with 100 units of SmaI for $6 \mathrm{~h}$ (all restriction enzymes were from New England Biolabs). The DNA was then digested with 20 units of XmaI for $16 \mathrm{~h}$, and the DNA fragments were precipitated with ethanol. RMCA PCR adaptors were prepared by incubation of the oligonucleotides, RMCA24 (5'-CCACCGCCATCCGAGCCTTTCTGC-3') and RMCA12 (5'-CCGGGCAGAAAG-3'), at $65^{\circ} \mathrm{C}$ for $2 \mathrm{~min}$, followed by cooling to room temperature. DNA $(0.5 \mu \mathrm{g})$ was ligated to $0.5 \mathrm{nmol}$ of RMCA adaptor using T4 DNA ligase (New England Biolabs). PCR was performed using $3 \mu \mathrm{l}$ of each of the ligation mixes as a template in a final volume of $100 \mu$ l containing 100 pmol of RMCA24 primer, 5 units of Taq DNA polymerase (Life Technologies), $4 \mathrm{mM} \mathrm{MgCl}_{2}, 16 \mathrm{mM}$ of $\mathrm{NH}_{4}\left(\mathrm{SO}_{4}\right)_{2}, 10 \mathrm{mg} / \mathrm{ml}$ of BSA and $5 \% \mathrm{v} / \mathrm{v}$ DMSO. The reaction mixture was incubated at $72^{\circ} \mathrm{C}$ for $5 \mathrm{~min}$ and at $95^{\circ} \mathrm{C}$ for $3 \mathrm{~min}$. Samples were then subjected to 25 amplification cycles consisting of $1 \mathrm{~min}$ at $95^{\circ} \mathrm{C}$ and $3 \mathrm{~min}$ at either $72^{\circ} \mathrm{C}$ or $77^{\circ} \mathrm{C}$, in a thermal cycler. The final extension time was $10 \mathrm{~min}$. The PCR products were resolved by electrophoresis on $1 \%$ agarose gel and stained with ethidium bromide.

The MCA amplicons obtained from the NP were cloned into the TOPO TA Cloning ${ }^{\circledR}$ kit (Invitrogen) and sequenced. Sequencing was performed by Dye Termination in a DNA sequencer(ABIPRISM377; both fromApplied Biosystems). The nucleotide sequences were compared with GenBank sequences using the Nucleotide BLAST program (http://www.ncbi.nlm. nih.gov/blast/) of the National Cancer Center for Biotechnology Information, and BLAT - the BLAST-like alignment tool (http:// genome.ucsc.edu/cgi-bin/hgBlat?command=start), found at the UCSC Genome Bioinformatics site.

Validation by quantitative real-time RT-PCR. Differentially methylated genes in NP were selected for experimental validation of their differential expression by RT-qPCR. Gene-specific 
Table II. Primer sets used for validation by RT-qPCR amplification.

\begin{tabular}{|c|c|c|c|}
\hline Gene & Primers 5'-3' & Primer concentration $(\mu \mathrm{M})$ & Base pair (bp) \\
\hline TUBAIC & $\begin{array}{l}\text { 5'-TCAACACCTTCTTCAGTGAAACG } \\
\text { 5'-AGTGCCAGTGCGAACTTCATC }\end{array}$ & 0.50 & 150 \\
\hline$A T P 2 A 1$ & $\begin{array}{l}\text { 5'-GGAAATGGTCCTGGATGACTCT } \\
\text { 5'-CGGCACAGCTGGATGGA }\end{array}$ & 0.75 & 123 \\
\hline NOVAl & $\begin{array}{l}\text { 5'-GCAGCACCAAGAGGACCAAT } \\
\text { 5'-CCCAATTATAGATCCAGCAGCAT }\end{array}$ & 0.40 & 89 \\
\hline PLCD3 & $\begin{array}{l}\text { 5'-CCAACTACAGTCCCCAGGAG } \\
\text { 5'-CTGCCCATTGACTAGGAAGC }\end{array}$ & 0.40 & 116 \\
\hline SOLH & $\begin{array}{l}\text { 5'-GACAGCTTCAACGTGGTGTC } \\
\text { 5'-TGGGACAAGATCACCAGGAC }\end{array}$ & 0.30 & 92 \\
\hline$T G F \beta I$ & $\begin{array}{l}\text { 5'-GCCAGCACTATGAGGAGGAG } \\
\text { 5'-CGCTAGATTGCAGTCCTTCC }\end{array}$ & 0.40 & 107 \\
\hline
\end{tabular}

primers for real-time PCR were designed for optimal hybridization kinetics using the Primer 3.0 program (provided by the Whitehead/MIT Center for Genome Research, Cambridge, MA, USA). Amplification primers were designed using different exons to avoid the amplification of contaminating genomic DNA. The primer sequences are shown in Table II. For validation, we used $11 \mathrm{NP}$ samples and a pool of total RNA from a subset of 13 nasal mucosa samples from human autopsies defined as the normal reference.

Real-time PCR was performed using an ABI PRISM 7300 Sequencer Detector system and SYBR Green PCR Core Reagent (Applied Biosystems) following the manufacturer's protocol. In brief, the reaction mixture $(20 \mu 1$ total volume) contained $25 \mathrm{ng}$ of cDNA, gene-specific forward and reverse primers for each gene, and $10 \mu \mathrm{l}$ of $2 \mathrm{X}$ Quantitative SYBR Green PCR Master Mix. Relative quantification was determined by the CT method, with values derived from triplicate reactions for the NP samples and the reference sample from each gene, and for the endogenous control ( $\alpha$-tubulin; TUBA1C). The concentrations of primers used were $0.3 \mu \mathrm{M}$ (SOLH), $0.4 \mu \mathrm{M}$ (NOVA1, PLCD3 and TGF $\beta I), 0.5 \mu \mathrm{M}$ (TUBA1C) and $0.75 \mu \mathrm{M}(A T P 2 A 1)$.

Thus, the relative expression of each specific gene was calculated as described previously (9) using the formula:

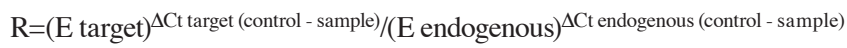

Statistical analysis of quantitative real-time RT-PCR data. Statistical analysis was performed using Minitab Student 14 software, and the significance level was set at $\mathrm{P} \leq 0.05$. Relative expression levels detected by quantitative real-time RT-PCR for the six genes in the NP samples were transformed into natural logarithms. The Anderson-Darling Normality test was then performed to determine whether the values presented a normal distribution or not. The Student's t-test was used to assess the data to identify differences in the expression levels of the genes.

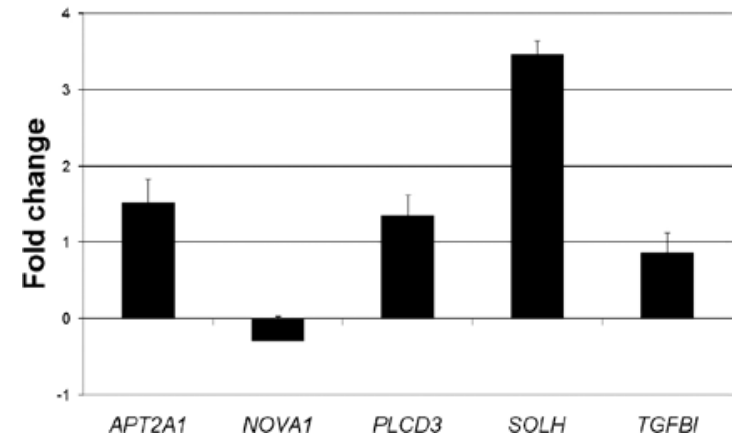

Figure 1. Relative expression values of the selected genes for validation by quantitative real-time RT-PCR. Expression of genes ATP2A1, NOVA1, $P L D C 3, S O L H$ and TGF $B$ I was significantly higher in NP compared to the normal reference (nasal mucosa). NOVAl was not overexpressed in NP.

\section{Results}

For MCA, as described above, the NP samples were pooled and then the DNA was digested and amplified with specific RMCA12 and RMCA24 primers. A smear was observed between 200 and 1,000 bp. The digested DNA was cloned, and all clones with the DNA of interest were sequenced and analyzed using the bioinformatics tools BLAST and BLAT. BLAST and BLAT searches of each clone confirmed that all were homologous to GenBank sequences located in the highthroughput genomic sequence database.

In the DNA homology search, five clones were found to be identical to known human gene sequences (Table III). These five clones presented homology to the genes ATP2Al (ATPase, $\mathrm{Ca}^{+2}$ transporting, cardiac muscle, fast twitch 1), NOVA1 (neuro-oncological ventral antigen 1), PLCD3 (phospholipase C, 83 ), SOLH (small optic lobes homologue) and TGF $\beta I$ (transforming growth factor, $\beta$-induced, $68 \mathrm{kDa}$ ). The differentially methylated sequences were confirmed to be 
present in the studied tissue, since only sequences with methylated $\mathrm{CpG}$ islands are amplified by this technique. Table III presents the results of an analysis using the CpG Island Search bioinfomatics tool to determine whether the genes in question presented $\mathrm{CpG}$ islands.

The five genes determined to be differentially methylated (ATP2A1, NOVA1, PLDC3, SOLH and TGF $\beta I$ ) were validated by quantitative real-time RT-PCR. When the relative expression levels of the genes were compared using triple determination and normalized based on $\alpha$-tubulin, the results showed that the ATP2A1, PLCD3, SOLH and TGF $\beta I$ genes were statistically overexpressed in the NP samples as compared to the reference sample. Only the NOVAl gene was not differentially expressed. Relative gene expression data are presented in Fig. 1.

\section{Discussion}

Nasal polyposis represents a real challenge for otorhinolaryngologists, as many questions about this disease remain unanswered. The pathogenesis of NP is to date unknown, treatment with antibiotics, steroids and even surgery is typically unsatisfactory, and the recurrence rate is unacceptably high (10). Genetic susceptibility, infection, anatomic abnormalities and local immunologic imbalances have been postulated to play a role in its pathogenesis (11). Although numerous studies have recently dealt with the pathogenesis of this nasal disease, the molecular alterations required for its development and progression have yet to be well understood (12).

With the aim of identifying novel genes differentially expressed in NP, we applied quantitative real-time PCR, which allows for the identification of specific genes and signaling pathways involved in the regulation of the disease process (13). This methodology has recently achieved a level of sensitivity, accuracy and practical ease that supports its use as a routine bioinstrumentation for gene level measurement (14).

For the selection of genes to be examined, the methylated $\mathrm{CpG}$ island amplification (MCA) technique was applied. MCA is a useful technique for studying methylation and for isolating differentially methylated $\mathrm{CpG}$ islands, and affords a better understanding of the pathophysiological mechanisms involved in NP (8).

In this study, only 11 patients diagnosed with NP over a period of one year gave their written informed consent for participation in the study. The same occured with the control patients, as most families did not consent to the extraction of the tissue. However, this low number of samples was sufficient for the MCA and subsequent validation of the genes by realtime PCR.

Using MCA, we identified five differentially methylated clones with methylated CpG islands in NP: ATP2A1, NOVA1, $P L D C 3, S O L H$ and TGF $\beta I$. We then analyzed their expression in NP and in normal mucosa by real-time PCR. The ATP2A1, $P L D C 3, S O L H$ and TGF $\beta I$ genes were overexpressed in NP, while NOVA1 presented no difference in expression between NP and normal mucosa. It was not possible to determine whether the expression of the genes was regulated by their hypermethylated CG-rich sequences in the normal mucosa.

Clusters of $\mathrm{CpG}$ sites are occasionally present in the genome and are designated as $\mathrm{CpG}$ islands. Although tradi- 
tionally $\mathrm{CpG}$ islands have been considered to be located in the 5 ' regions of genes, they are actually located at various positions throughout the genes, such as in exons and introns or further downstream (15). The ATP2A1, PLCD3, SOLH and $T G F \beta I$ genes present methylated $\mathrm{CpG}$ islands between exons 3 and 4 , between exons 1,2 and 3 , from exon 1 to 4 and in exon 1 , respectively. These positions are not in the promoter regions of the genes. Therefore, there are other mechanisms regulating the expression of these genes, since the presence of hypermethylation in these exons could not have been responsible for regulating their expression in NP once they were overexpressed in our samples.

The ATP2A1 gene, located at 16p12.1, was up-regulated in $91 \%$ of the NP samples compared to the normal tissue samples. Notably, extra copies of chromosome 16 were found in nasal polyps by Vanni et al (16) and Speleman et al (17). Chromosome gain contributes to the overexpression of genes. Therefore, these cytogenetic findings corroborated those of the present study.

The ATP2A1 gene encodes a protein named SERCA that catalyzes the transport of $\mathrm{Ca}^{+2}$ from the cytosol into the lumen of the endoplasmic reticulum (18). SERCA is found in the membrane of the sarcoplasmic reticulum and is responsible for catalyzing the hydrolysis of ATPs for the transport of $\mathrm{Ca}^{+2}$ ions of the cytosol into the lumen of the sarcoplasmic reticulum for muscular excitation and contraction. Mobilization of the $\mathrm{Ca}^{+2}$ ions from the sarcoplasmic reticulum into the cytosol is a key component of the control of tumoral growth, apoptosis and cell differentiation (19), events involved in the formation and establishment of nasal polyps. Ion transport mechanisms altered due to chemical mediators found in the extracellular fluid, mainly histamins, increase the vascular permeability, modifying the electrolyte transport in the cellular membrane and leading to the formation of edema (20).

The PLCD3 gene, located at 17q21.31, was up-regulated in $91 \%$ of the NP samples compared to the normal tissue samples. Extra copies of chromosome 17 were also found in nasal polyps in the study of Speleman et al (17), further corroborating the cytogenetic findings of the present study. This gene encodes a protein called phospholipase C 83 , which is located in the cell membrane and is involved in cell membrane signaling. Control of PLCD3 activity is one of the major starting points of cell regulation $(21,22)$. Therefore, its biological function is involved in the control of the cell cycle by means of the activation of protein kinase $\mathrm{C}$, intracellular storage of $\mathrm{Ca}^{+2}$ ions, signal transduction, and transport through the cell membrane.

In the present study, the PLCD3 gene was up-regulated in $100 \%$ of the NP samples, suggesting that its function is related to the formation and/or development of NP. It is known to be related to cell cycle control, an important process in cell proliferation, apart from its function in signal transduction, which is important in the permanent recruitment of inflammatory cells, mainly eosinophils (4).

The $S O L H$ gene, also located at 16p13.3, was up-regulated in $100 \%$ of the NP samples as compared to the normal tissue. This gene is homologous to the small optic lobes (SOL) gene of Drosophila melanogaster. In D. melanogaster, this gene is involved in development and behavior. Mutations in SOL cause a severe reduction in the cell numbers of neutrophils of the medulla and lobula complexes of the adult optic lobes.
Sparse knowledge exists regarding the function of this gene in humans. Kamei et al (23) suggested that the SOLH gene may have an analogous function in the sensorial development of mammals. It is possible that modified expression of this gene is related to alterations in the sensorial system, such as olfactory loss in patients with NP.

The TGF $\beta I$ gene is located in the chromosome region $5 q 31$ (24). Extra copies of chromosome 5 were found in nasal polyps by Vanni et al (16) and Speleman et al (17), correlating the cytogenetic findings with ours. This gene presents 17 exons coding for a single protein of 683 amino acids, which is produced by both mesenchymal and epithelial cells and is denoted as keratoepithelin (KE) (25). Although the precise function of KE is not known, its sequence suggests a potential role in cell adhesion due to its homology with two cell adhesion molecules. NP is characterized by cell proliferation and the infiltration of inflammatory cells, processes that require cell adhesion molecules for the formation and establishment of nasal polyps. In the present study, $T G F \beta I$ was up-regulated in $82 \%$ of the NP samples, verifying its involvement in this pathology.

Using real-time PCR, this study showed an increase in the expression of the ATP2A1, PLDC3, SOLH and TGF $\beta I$ genes in nasal polyps. These genes are involved in cellular processes such as tumor growth, apoptosis, cell differentiation, signal transduction and control of the cell cycle, sensorial development and cell adhesion. These cellular processes play important roles in the formation of nasal polyps, which result in abnormal cell proliferation followed by edema and the recruitment of inflammatory cells.

At present, the biology of nasal polyps remains unclear, nor is it known which genes participate in NP formation and development. The genes identified in this study are probably involved in some stage of the process of the formation and development of nasal polyposis, as they were highly expressed in the NP samples. To confirm whether these genes have a definitive function in NP and to determine their exact function in the pathogenesis of the disease, further study is required.

\section{Acknowledgements}

This study was financially supported by The State of São Paulo Research (FAPESP), The National Council for Scientific and Technological Development (CNPq) and the Coordination for the Improvement of Higher Education Personnel (CAPES).

\section{References}

1. De Castro MC, Assunção E, de Castro MM, Araújo RN, Guimarães RE and Nunes FB: Effect of mitomycin C in eosinophilic nasal polyposis, in vivo: concentration of IL5 and GM-CSF, RT-PCR. Rev Bras Otorrinolaringol 72: 38-42, 2006.

2. Fokkens WJ, Lund VJ and Mullol J: European Position Paper on Rhinosinusitis and Nasal Polyps Group. European Position Paper on Nasal Polyps 2007. Rhinology 45: 1-139, 2007.

3. Norlander T, Brönnegård $\mathrm{M}$ and Stierna $\mathrm{P}$ : The relationship of nasal polyps, infection and inflammation. Am J Rhinol 13: 349-355, 1999.

4. Pawankar R: Nasal polyposis: an update: editorial review. Curr Opin Allergy Clin Immunol 3: 1-6, 2003.

5. Sena AA, Provazzi PJ, Fernandes AM, Cury PM, Rahal P and Oliani SM: Spatial expression of two anti-inflammatory mediators, annexin 1 and galectin-1, in nasal polyposis. Clin Exp Allergy 36: 1260-1267, 2006. 
6. Saunders MW, Wheatley AH, George SJ, Lai T and Birchall MA Do corticosteroids induce apoptosis in nasal polyp inflammatory cells? In vivo and in vitro studies. Laryngoscope 109: 785-790, 1999.

7. Badia $\mathrm{L}$ and Lund V: Topical corticosteroids in nasal polyposis. Drugs 61: 573-578, 2001.

8. Toyota M, Ho C, Ahuja N, et al: Identification of differentially methylated sequences in colorectal cancer by methylated $\mathrm{CpG}$ island amplification. Cancer Res 59: 2307-2312, 1999.

9. Pfaffl MW: A new mathematical model for relative quantification in real-time RT-PCR. Nucleic Acids Res 29: e45, 2001.

10. Tuncer U, Soylu L, Aydogan B, Karakus F and Akcali C: The effectiveness of steroid treatment in nasal polyposis. Auris Nasus Larynx 30: 263-268, 2003.

11. Sheppard D: Uses of expression microarrays in studies of pulmonary fibrosis, asthma, acute lung injury and emphysema: Roger S. Mitchell lecture. Chest 121: S21-S25, 2002.

12. Liu Z, Kim J, Sypek JP, et al: Gene expression profiles in human nasal polyp tissues studied by means of DNA microarray. J Allergy Clin Immunol 114: 783-790, 2004.

13. Lee SH, Park JH, Jung HH, et al: Expression and distribution of ion transport mRNAs in human nasal mucosa and nasal polyps. Acta Otolaryngol 125: 745-752, 2005.

14. Provenzano $\mathbf{M}$ and Mocellin S: Complementary techniques: validation of gene expression data by quantitative real time PCR Adv Exp Med Biol 593: 66-73, 2007.

15. Ushijima $\mathrm{T}$ and Okochi-Takada E: Aberrant methylations in cancer cells: Where do they come from? Cancer Sci 96: 206-211, 2005.

16. Vanni R, Medda C, Marras S, Gaudio RM and Faa G: Numerical chromosome changes in a nasal polyp. Genes Chromosomes Cancer 10: 203-206, 1994.

17. Speleman F, de Potter C, van Roy N and Laureys G: Multiple polysomies in nasal polyps in children. Cancer Genet Cytogenet 90: 86-87, 1996
18. Asahi M, Sugita Y, Kurzydlowski K, et al: Sarcolipin regulates sarco(endo)plasmic reticulum $\mathrm{Ca}^{+2}$-ATPase (SERCA) by binding to transmembrane helices alone or in association with phospholamban. Proc Natl Acad Sci USA 100: 5040-5045, 2003.

19. Gélébart P, Kovács T, Brouland JP, et al: Expression of endomembrane calcium pumps in colon and gastric cancer cells Induction of SERCA3 expression during differentiation. J Biol Chem 277: 26310-26320, 2002.

20. Rudack C, Prehm P, Stoll W and Maune S: Extracellular matrix components in nasal polyposis. Acta Otolaryngol 123: 643-647, 2003.

21. Pawelczyk T and Matecki A: Localization of phospholipase $\mathrm{C}$ delta3 in the cell and regulation of its activity by phospholipids and calcium. Eur J Biochem 257: 169-177, 1998.

22. Pawelczyk T and Matecki A: Phospholipase C-delta3 binds with high specificity to phosphatidylinositol 4,5-bisphosphate and phosphatidic acid in bilayer membranes. Eur J Biochem 262: 291-298, 1999.

23. Kamei M, Webb GC, Heydon K, Hendry IA, Young IG and Campbell HD: Solh, the mouse homologue of the Drosophila melanogaster small optic lobes gene: organization, chromosomal mapping and localization of gene product to the olfactory bulb. Genomics 64: 82-89, 2000.

24. Zenteno JC, Ramirez-Miranda A, Santacruz-Valdes C and Suarez-Sanchez R: Expanding the mutational spectrum in TGFBI-linked corneal dystrophies: identification of a novel and unusual mutation (Val113Ile) in a family with granular dystrophy. Mol Vis 12: 331-335, 2006.

25. Cung le X, Ha NT, Chau HM, et al: Mutation analysis of the TGFBI gene in Vietnamese with granular and Avellino corneal dystrophy. Jpn J Ophthalmol 48: 12-16, 2004. 